\title{
Mulheres da Norô
}

Flavia Liberman ${ }^{(a)}$

Luiza Maria Escardovelli Alcântara(b)

Nice Gonçalvez ${ }^{(c)}$

Viviane Santalucia Maximino(d)

Thais Marques Fidalgo ${ }^{(\mathrm{e})}$

Marina Guzzo(f)

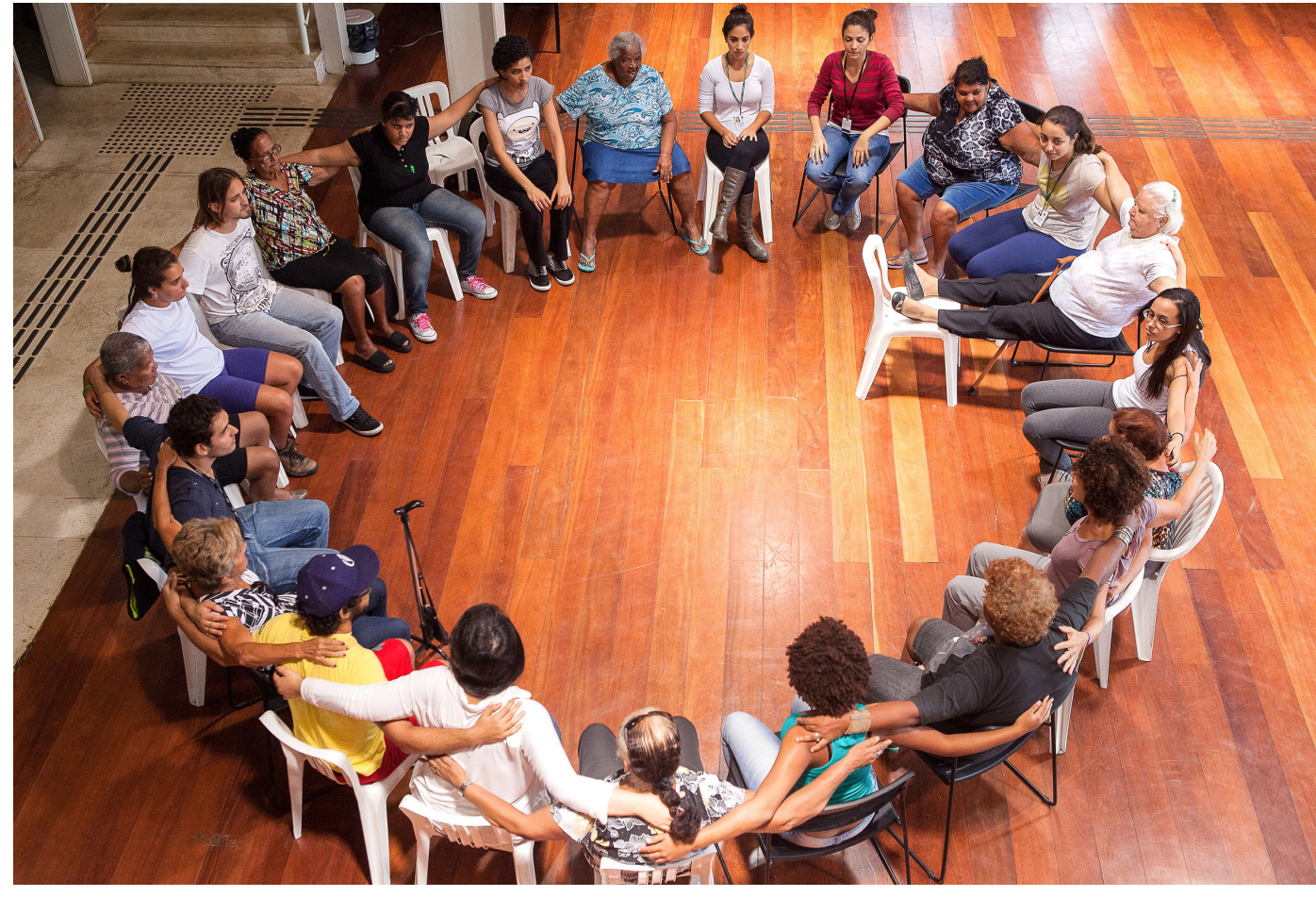

O que me surpreende é o fato de que, em nossa sociedade, a arte tenha se transformado em algo relacionado apenas a objetos, e não a indivíduos ou à vida; que arte seja algo especializado ou feita por especialistas que são artistas. Entretanto, não poderia a vida de todos se transformar numa obra de arte? Por que deveria uma lâmpada ou uma casa ser um objeto de arte, e não a nossa vida?'1 (p. 261)
* Exposição fotográfica financiada pela Fundação de Apoio à Universidade Federal de São Paulo, por meio do Programa Nacional de Assistência Estudantil Procultura Estudantil 2013 (Edital PRAE n० 05/2013); resultante do projeto de pesquisa "Cartografias femininas: ações territoriais junto às mulheres da região Noroeste de Santos", realizado na Universidade Federal de São Paulo (Unifesp), campus Baixada Santista e aprovado pelo Comitê de Ética.

(a,d,f) Departamento Saúde, Clínica e Instituições,

Unifesp, campus Baixada Santista. Rua Silva Jardim, 136. Santos, SP, Brasil. 11015-020. toflavia.liberman@ gmail.com; vivimax10@ yahoo.com.br; marinaguzzo2@ gmail.com

(b) Centro de Referencial da Assistência Social (CRAS).

Avanhandava, SP, Brasil. luiza.escardovelli@gmail.com

(c) Instituto Arte no

Dique. Santos, SP, Brasil. nice.negra@hotmail.com

(e) Associação de Pais e Amigos dos Excepcionais de São Vicente (APAE).

São Vicente, SP, Brasil. thais.fidalgo@hotmail.com 
Solange, Eunice, Ana, Fabi, Vera, Zefa, Maria...mulheres da Norô. Vivem em barracos precários, em palafitas sobre o rio Bugre, em vielas, em casinhas ajeitadas no pedaço residencial do bairro, no conjunto habitacional. Solteiras, casadas, muitas vezes enamoradas, viúvas, com filhos, vivos e mortos. Vieram de outras cidades, para trabalhar, acompanhando seus pais que migraram, sobretudo, do nordeste na década de 1970, vieram com seus companheiros fugindo de casas opressoras, da lavoura, da seca. Muitas já nasceram aqui, na zona noroeste de Santos, uma região bastante populosa e heterogênea. Na zona noroeste, encontramos de tudo: há serviços de saúde, alguns centros culturais e esportivos públicos e não governamentais, escolas, comércio, lixo, pontos de droga, disputas por territórios. É uma cidade dentro de outra, pois é assim que os moradores se sentem: vou para Santos, dizem.

Nossas Anas, Solanges, Veras e Fabis têm: artrose, escoliose, desvio no quadril, dores nas costas... têm nervosismo, tristeza, dificuldades financeiras, sequelas de "derrame", isolamento, desesperança, apatia. Têm também: força, alegria, senso de humor, esperança. Tudo isso fazendo uma beleza comovente, um pequeno poema nas nossas tardes de quarta-feira.

Vamos encontrando com elas nas esquinas, nos becos, em suas casas. Elas se arrumam para esperarem os "meninos" que vêm buscá-las com a van. São estudantes da Unifesp, do campus Baixada Santista, de vários cursos da área da saúde, que aprendem fazendo. Ao acompanhá-las no Grupo de Mulheres, aprendem a ouvir, a prestar atenção, a conversar sobre vidas tão diferentes das suas. Junto com as professoras, propõem diversas experimentações: danças, brincadeiras, movimentos - práticas corporais e artísticas em um espaço cultural localizado no Dique da Vila Gilda. No Instituto Arte no Dique, essas mulheres convivem com crianças e jovens, com oficinas de percussão, informática e diversas outras propostas.

No início, receosas de colocar seus corpos em movimentos desconhecidos, com muitas dificuldades para sair de casa por inúmeros motivos, aos poucos foram se permitindo a experimentação de novos sons, novas comidas, outras histórias. Foram se fortalecendo nas amizades, arriscando novos passos, ampliando sua potência. Ao acompanhá-las neste processo, os estudantes foram percebendo de quantas camadas se fazem as vidas, e como é necessário compreender a saúde como este movimento de mais vida e potência, de bons encontros que nos alegram.

O objetivo principal do projeto "Cartografias femininas: ações territoriais junto às mulheres da região noroeste de Santos" tem sido realizar ações em um território que apresenta vulnerabilidade social e ambiental. Como resultado destas ações em andamento, foi realizada uma exposição fotográfica itinerante das mulheres da região a partir de um processo de construção resultante dos vínculos estabelecidos com as mulheres envolvidas. A fotógrafa Nice Gonçalvez, do Instituto Arte no Dique (para saber mais acesse: http://www.artenodique.org/), acompanhou e fotografou, durante o ano de 2013, vários momentos da experiência, oferecendo-nos um material delicado e sutil, que retrata algumas das participantes do projeto com seus rostos, corpos, detalhes, expressividades (todas assinaram termo de consentimento de uso da imagem).

Viajando por vários lugares: do Dique para a universidade, em eventos científicos, espaços públicos, como na amostra em um shopping center de Santos no Dia da Mulher, e, mesmo, nas divulgações feitas na imprensa, esta exposição ofereceu às mulheres uma oportunidade de reconhecerem-se como protagonistas ativas e fortes em todo o processo, tornando-as visíveis para além das fronteiras de suas casas, de seu bairro ou, mesmo, de sua região.

Tudo era motivo de riso, de orgulho e de maior apropriação de si para muitas delas, que se viam nas imagens e puderam se re-ver. Já não se tratava de mostrar uma mulher em particular mas, por meio do conjunto de imagens fotográficas, fazer espraiar, pelos ambientes, um clima que emergia da presença das mulheres em diferentes situações registradas: um detalhe, um movimento, uma composição em roda, na captação de olhares, nos pés descascados ao lado do tênis de uma estudante, na bengala apoiada, enfim, nas fotos tiradas com sensibilidade, captando pequenos e breves acontecimentos.

Nas fotos a seguir, tratamos de caminhos-processos que formaram uma delicada narrativa feminina, artesanal, uma narrativa que é única e composta por muitas histórias. Uma narrativa capaz de produzir vidas, de produzir saúde e de realizar uma clínica fora de padrões institucionais, uma clínica artística e viva. 
워త요
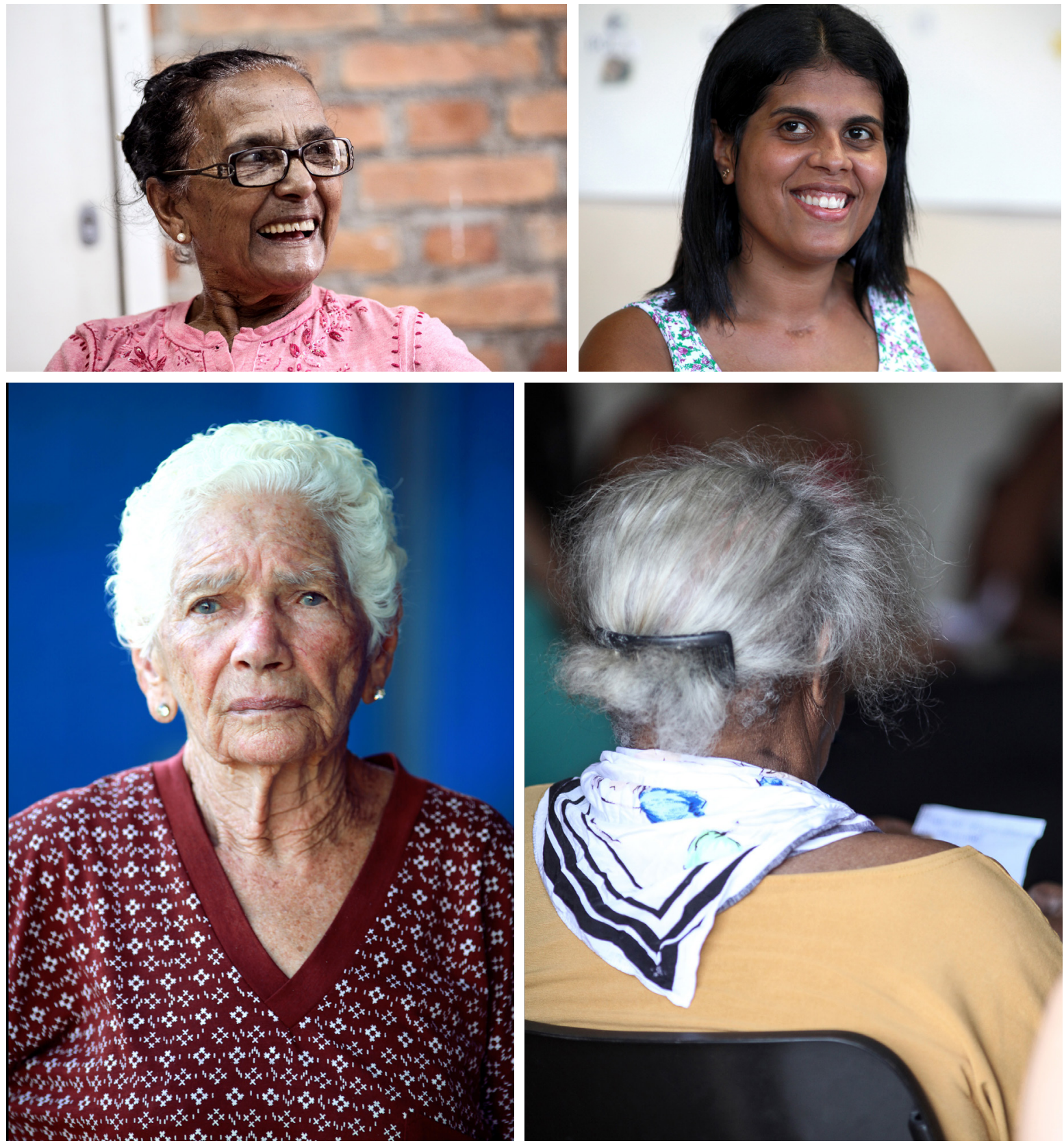

(อ) Interface comunicaçāo saúde educaçāo 

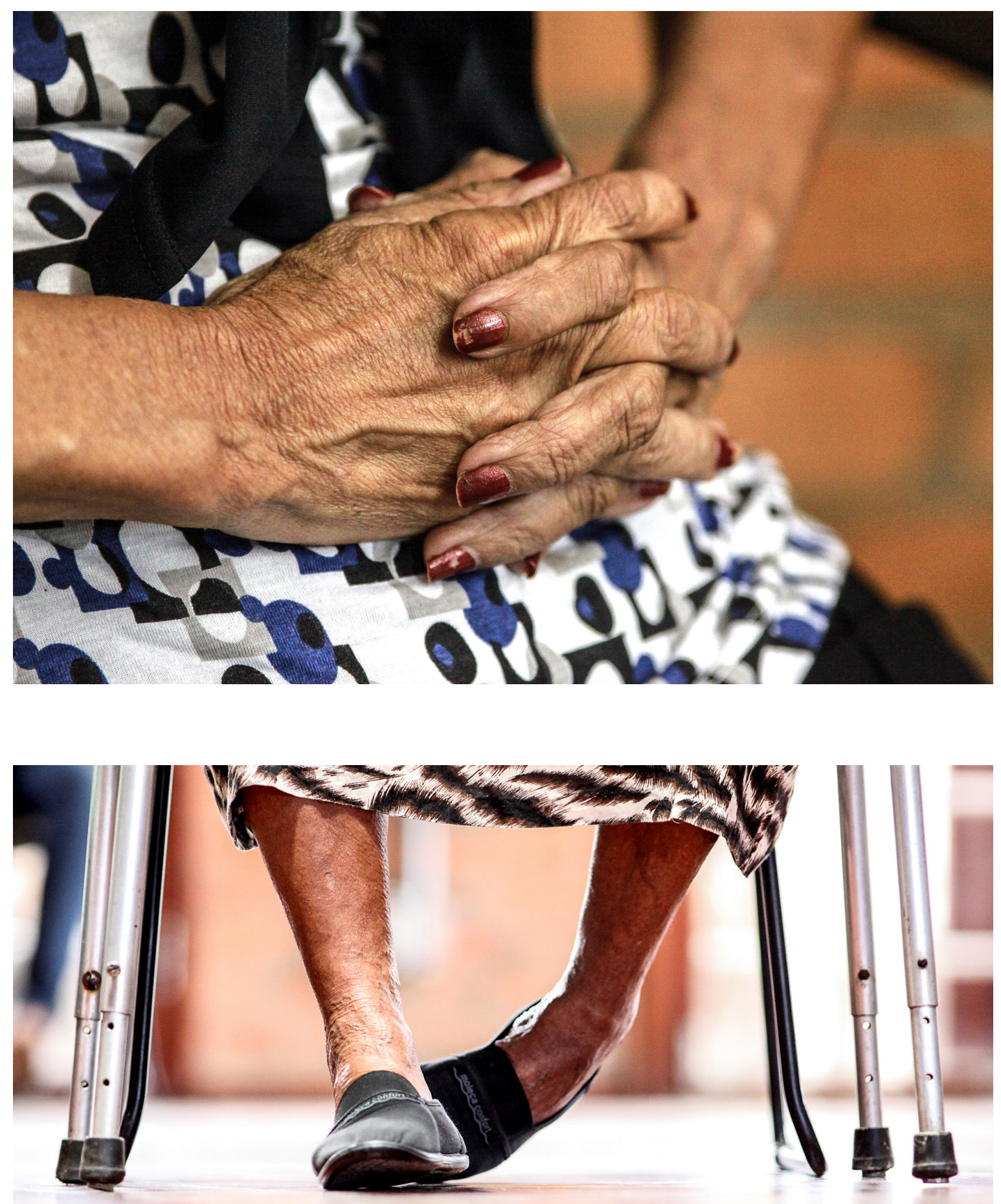


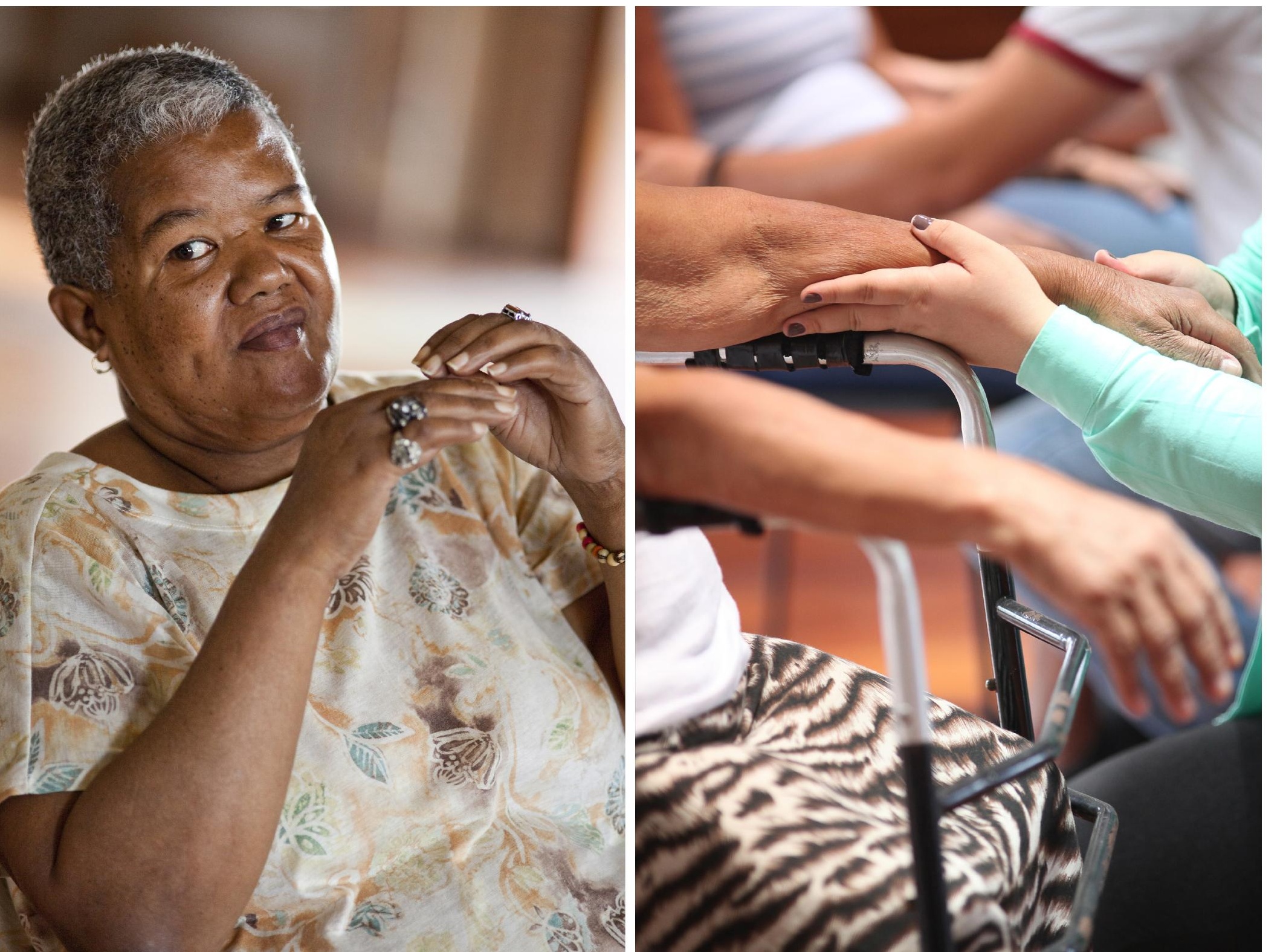




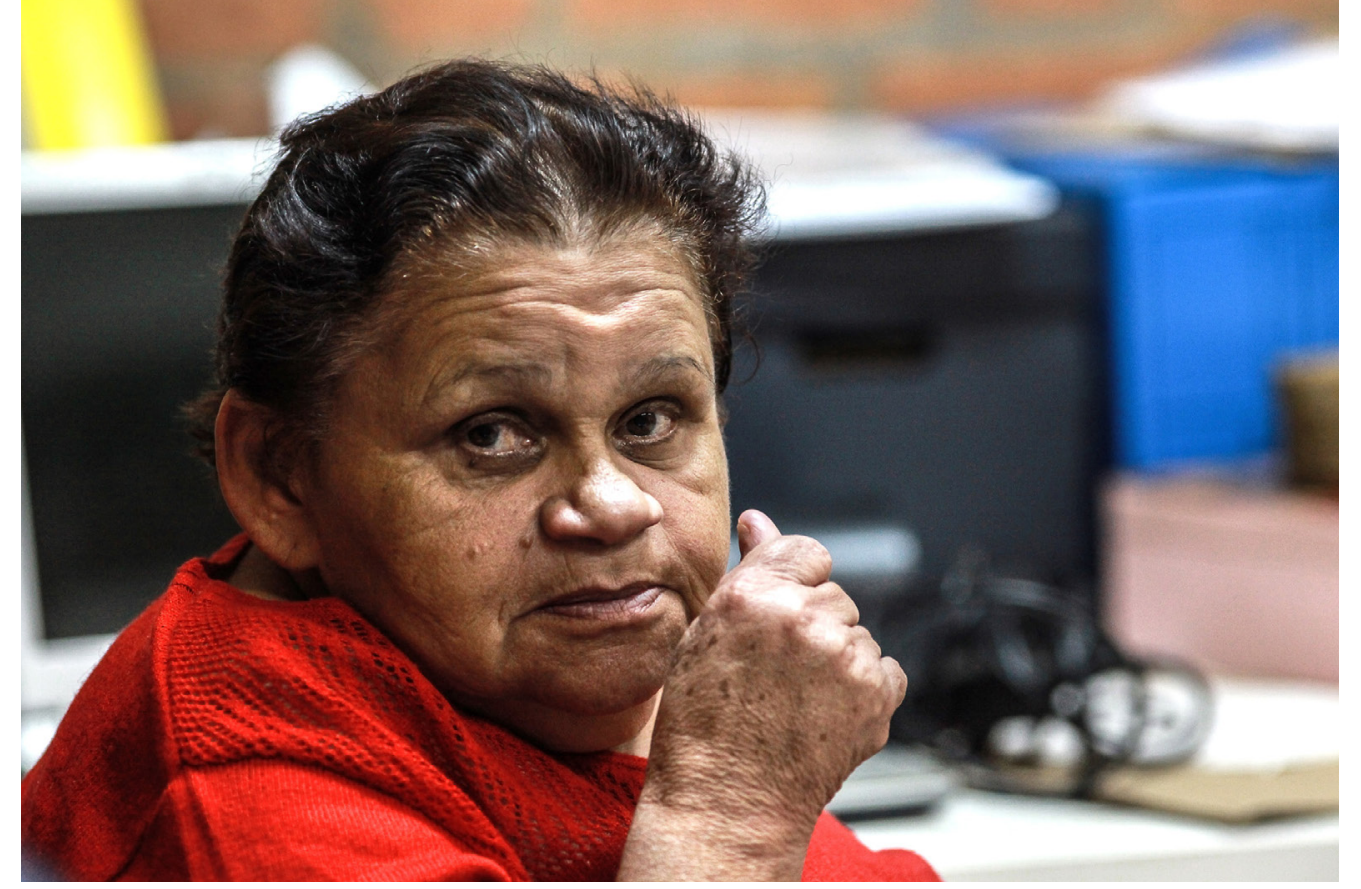

•엄원
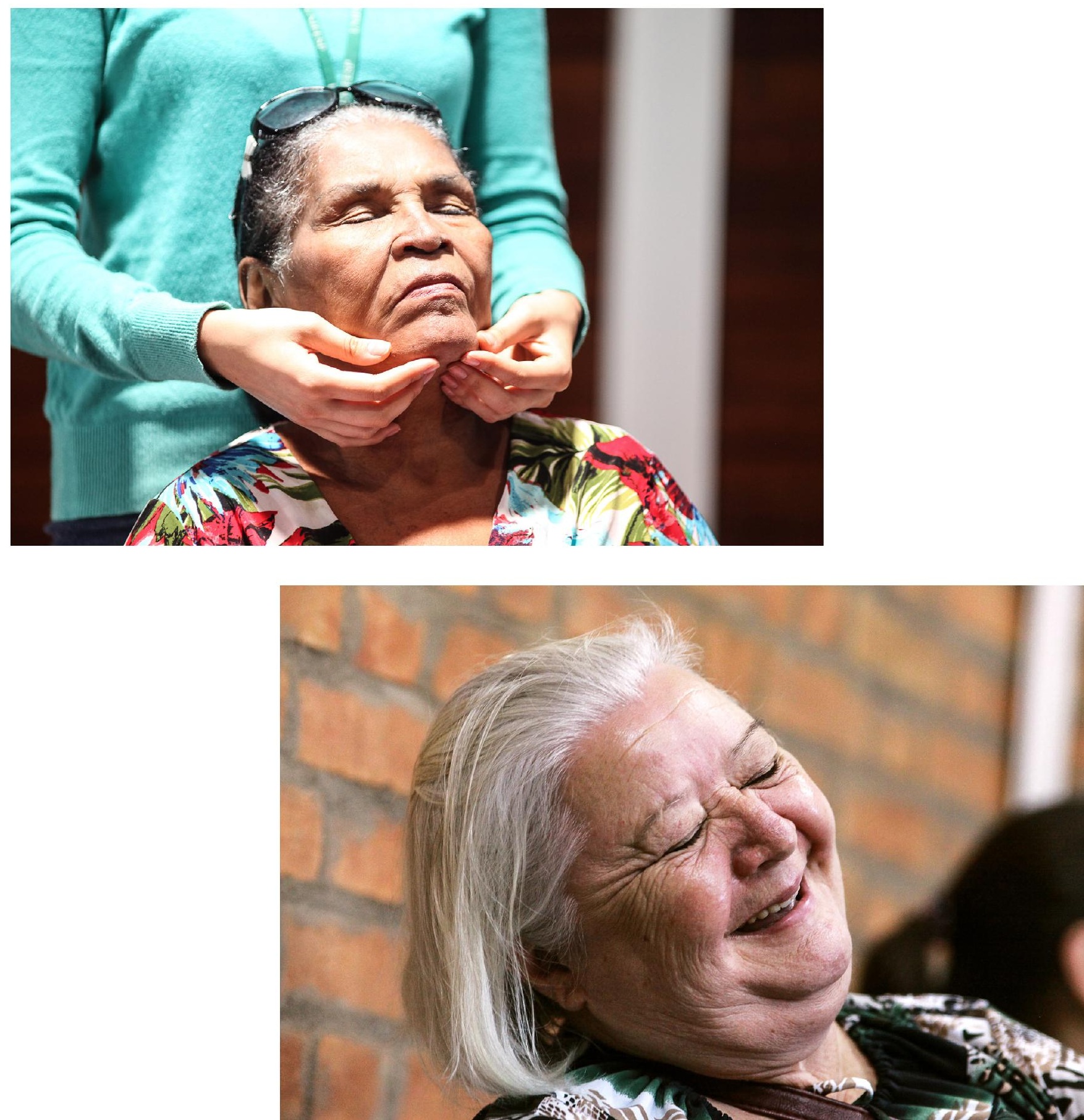

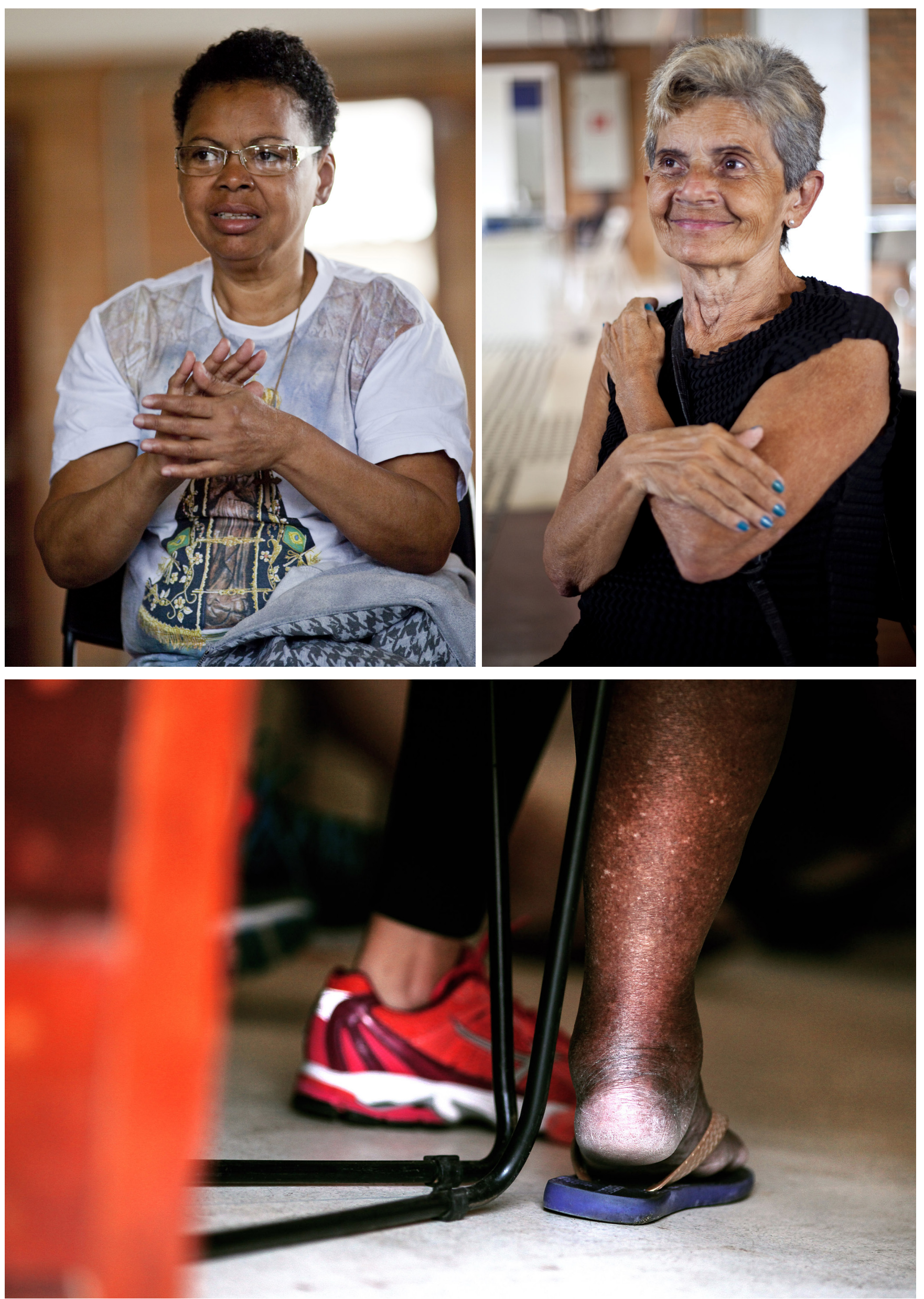

CRIAÇÃO

\section{Colaboradores}

Os autores participaram, igualmente, de todas as etapas de elaboração do artigo.

Referências

1. Foucault $M$. Sobre a genealogia da ética: uma revisão do trabalho. In: Dreyfus $H$, Rabinow P. Michel Foucault, uma trajetória filosófica. Para além do estruturalismo e da hermenêutica. Rio de Janeiro: Forense Universitária; 1995.

2. Favre R. Imagem-tempo e imagem-movimento [Internet]. São Paulo: Laboratório do processo formativo [citado 2 Abr 2016]. Disponível em: http:// laboratoriodoprocessoformativo.com/2016/04/imagem-tempo-e-imagem-movimento/\# Vv64yK9WXNs.facebook 
O projeto Cartografias femininas: ações territoriais junto às mulheres da região noroeste de Santos realiza diferentes ações em uma região que apresenta vulnerabilidade social e ambiental na cidade de Santos. Envolvendo docentes e estudantes de diferentes cursos de graduação da área da saúde da Universidade Federal de São Paulo, campus Baixada Santista, teve como resultado uma Exposição Fotográfica itinerante cujas imagens explicitam um processo de construção de vínculos com as participantes. A fotógrafa Nice Gonçalvez, do Instituto Arte no Dique, acompanhou e fotografou momentos desta experiência, oferecendo-nos um material delicado que retrata seus rostos, corpos, detalhes e expressividades. Esta exposição ofereceu, às mulheres, uma oportunidade de reconhecerem-se como protagonistas ativas e fortes em todo o processo, tornando-as visíveis para além das fronteiras de suas casas, de seu bairro ou, mesmo, de sua região.

Palavras-chave: Arte. Fotografia. Mulheres. Vulnerabilidade.

\section{Women of Norô}

The Femele Cartography: territorial actions with women in the northwest region of Santos does different actions in a region with social and environmental vulnerability in the city of Santos. Involving teachers and students from different undergraduate courses in the health area of the Federal University of São Paulo, campus Baixada Santista, and collaborators, the project had as one of its consequences one itinerant Photographic Exhibition whose images shows a process of building relationship established with the participants. The photographer Nice Gonçalvez, from Instituto Arte no Dique accompanied and photographed this experience offering a delicate and subtle material that depicts some of the project participants with their faces, bodies, detail and expressiveness. This exhibition offered the women an opportunity to recognize them as active and strong actors and in the process, making them visible beyond the confines of their homes, their neighborhood or even their region.

Keywords: Art. Photography. Women. Vulnerability.

\section{Mujeres de la Norô}

El Proyecto Cartografías Femeninas: Acciones territoriales con las mujeres de la región noroeste de Santos realiza diferentes acciones en una región que presenta vulnerabilidad social y ambiental en la ciudad de Santos. El envolvimiento de docentes y estudiantes de diferentes cursos de graduación del área de la salud de la Universidad Federal de São Paulo, campus Baixada Santista, tuvo como resultado una Exposición Fotográfica itinerante cuyas imágenes dejan explícita un proceso de construcción de vínculos con las participantes. La fotógrafa Nice Gonçalvez, del Instituto Arte no Dique, acompañó y fotografió momentos de esta experiencia, ofreciéndonos un material delicado que retrata sus rostros, cuerpos, detalles y expresividades. Esta exposición ofreció a la mujeres la oportunidad de reconocerse como protagonistas activas y fuertes en todo el proceso, haciéndolas visibles más allá de las fronteras de sus casas, de su barrio o incluso de su región.

Palabras clave: Arte. Fotografía. Mujeres. Vulnerabilidad. 